\title{
MATURITY RATING OF INFORMATION TECHNOLOGY GOVERNANCE FOR STATE OWNED ENTERPRISES (SOE)
}

\author{
Ayu Kartika (Corresponding author) \\ Information System Department, Bandar Lampung University \\ Jl. Z.A. Pagar Alam No 26, Labuhan Ratu, Bandar Lampung \\ Tel: +6285710671068 E-mail: ayukartikapuspa@ubl.ac.id \\ Yuthsi Aprilinda \\ Informatics Department, Bandar Lampung University \\ J1. Z.A. Pagar Alam No 26, Labuhan Ratu, Bandar Lampung \\ Tel: +6282185972890 E-mail: yuthsi.aprilinda@ubl.ac.id
}

\begin{abstract}
This research is motivated by the importance of Information Technology Governance (IT Governance). It is necessary to know the absolute value of a company based on maturity level, it is necessary to know how to improve maturity model level, and control the performance of Human Resources (HR). The purpose of this research is to give the achievement level of maturity level of Domain Planning and Organization (PO) and Acquire and Implement (AI) as well as to provide solution from each level of maturity based on Cobit 4.1 framework using governance application information technology using the Cobit 4.1 framework. This study does not address the domains of Deliver and Support and Monitor and Evaluate. This research uses a qualitative approach. The application created in this writing is desktop-based application. In the manufacturing process required initial design of the application that is presented through the interface design. By using this application, it is expected to assist the management in controlling the existing technology and human resources infrastructure and the management can evaluate the current organizational maturity level position (as-is) and the future expectation (to-be).
\end{abstract}

Keywords - Interface, IT Governance, maturity level, planning and organization, acquire and implement, framework, Cobit 4.1, as-is, to-be

DOI: $10.7176 /$ CTI/8-07

\section{Introduction}

The development of information technology that has grown from time to time has had an impact on human life in all aspects. Technology is no longer a common thing, but it has become the need of everyone. Even in its implementation, technology has played an important role in various performance and existing business, especially in increasing the level of corporate competition in the wheels of the economy by both business and government and society.

In its use, the role of information technology cannot be separated from top management control, to be able to bring the company forward to the expected future level. To achieve these objectives, there is a need for a mature information technology management to arrive at its implementation, starting from the required resources, investing the funds spent and certainly adequate information technology infrastructure. Therefore, there is a need for good organizational information technology governance so that companies are not wrong in stepping and making choices and decisions so that the plans that have been made by the management can be controlled and run maximally.

Cobit is the most comprehensive and comprehensively assessed standard as an IT audit framework as it is developed on an ongoing basis by professional auditing professionals spread across the country (Weber, 1999). Cobit framework also has a framework that can be used as a directive in auditing. These include Control Objectives, Audit Guidelines, Management Guidelines, and maturity models. Cobit also emphasizes regulation, improves the value to be achieved from IT, and IT implementation arrangements.

The Case study taken in this research is the company in the form of ownership / BUMN (Persero). Referring to the Minister of State-Owned Enterprise Regulation No.PER-02 / MBU / 2013stated that the IT governance audit is set within a quarterly or every 1 year period that is aligned with the Company's Long Term Plan (RJPP) and the Company's Work Plan and Budget (RKAP) and the target level of maturity level of State Owned Enterprises (SOE) is at least at maturity level 3. 
Based on the above background description, it can be seen that information technology governance is needed and expected to be a guideline and standard in internal audit organization in SOE companies. Thus, through these issues, the authors are encouraged to build "The Information Technology Governance Application Using the Cobit 4.1 Domain Planning and Organization (PO) and Acquire and Implement (AI) Framework.

\subsection{Problem Identification}

a) The Importance of Information Technology Governance (IT Governance).

b) It takes the absolute value of the company based on maturity level (maturity level).

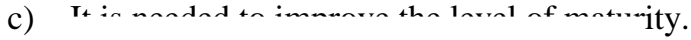

d) Table 3.1 Assessment of Cobit Index sources (HR) according to the existing description of the task (job aescripuion).

\subsection{Scope of the Problem}

a) This study covers only the Planning and Organization (PO) and Acquire and Implement (AI) domains.

b) This study does not address the domains of Deliver and Support (DS), and Monitor and Evaluate (ME).

c) This research was conducted with Cobit 4.1 framework.

d) The measurement of maturity level uses Cobit 4.1 framework.

e) The type of company studied is a State Owned Enterprises (SOE).

f) Internal audit evaluation of the organization is valid for 1 year.

\subsection{Problem Formulation}

a) How to determine the scale of the company's maturity level?

b) Whether with this application the management will be easy in making decisions related to information technology governance (TKTI)?

c) Will the company's strategic goal be achieved?

d) What is the information technology management standard that complies with the Cobit 4.1 framework?

\subsection{Research Objectives}

a) Create a desktop-based information technology governance application.

b) Determine the decision steps to be taken by the management.

c) Determining the company's future business strategies.

d) Establishing business goals in the management planning process.

\section{Research methods}

In this study, data was collected by using library study and documentation. The research method used by the writer is Cobit 4.1 framework.

This study used the measurement scale to determine the high level of maturity level by using Cobit maturity level scale 4.1. The table of Cobit maturity level scale is asfollows.

\begin{tabular}{|c|c|}
\hline $\begin{array}{c}\text { Absolute Value } \\
\text { (Assessment Index) }\end{array}$ & $\begin{array}{c}\text { Level Model } \\
\text { Maturity } \\
\text { No initialization }\end{array}$ \\
\hline 0 & Initialization \\
\hline 1 & Repeated \\
\hline 2 & Defined \\
\hline 4 & Set \\
\hline 5 & Optimalized \\
\hline
\end{tabular}

Here is the scale rating of Cobit's rounding off level of maturity, according to ISACA consisting of 6 level levels. 


\begin{tabular}{|c|l|}
\hline $\begin{array}{c}\text { Rounding } \\
\text { Scale }\end{array}$ & \multicolumn{1}{|c|}{$\begin{array}{c}\text { Level of } \\
\text { Maturity }\end{array}$} \\
\hline $4,51-5,00$ & $5-$ Optimalized \\
\hline $3,51-4,50$ & $4-$ Set \\
\hline $2,51-3,50$ & $3-$ Defined \\
\hline $1,51-2,50$ & $2-$ repeatable \\
\hline $0,51-1,50$ & $1-$ Initialized \\
\hline $0,00-0,50$ & $0-$ No initialization \\
\hline
\end{tabular}

To calculate the overall level of Cobit maturity level, the following formula is used:

$$
\text { Index }=\sum \frac{\text { totalanswerfromqustionnaire }}{\text { totalquestionsfromquestionnaire }}
$$

\section{Result and Discussion}

\subsection{Captures of The Application}

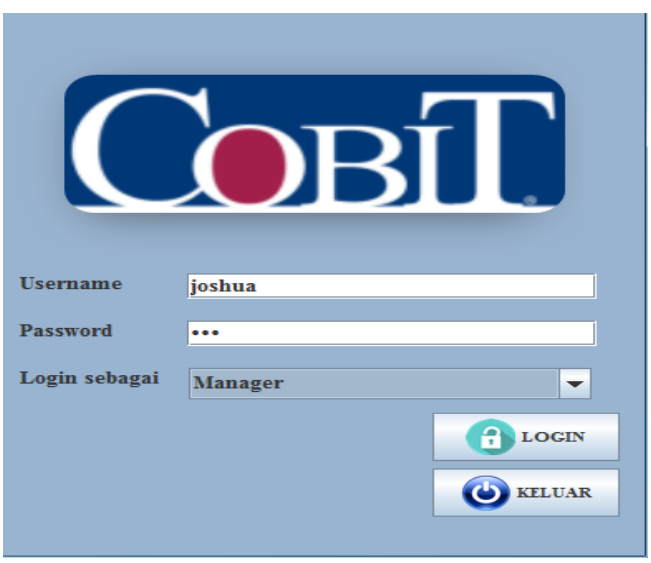

The picture above is the login page screen for manager and admin. Manager or admin enters the system by filling in username and password and choosing login as manager or admin, and the Exit button is used to exit the application.

a. Company Input Profile Page

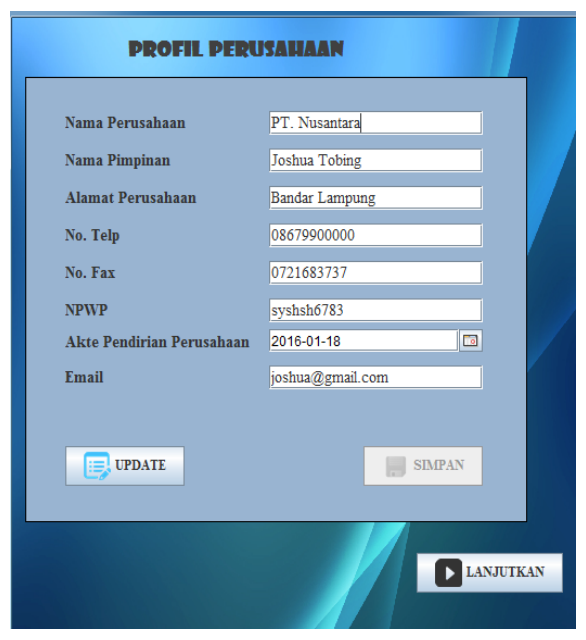


The picture above is the page screen of the company's profile filled by the manager. The save button is used to store company profile data when first filling. The Update button is used to modify data that has been saved, for which data can be updated. When finished click the go button, to go to the main page.

\section{a. Main Page}

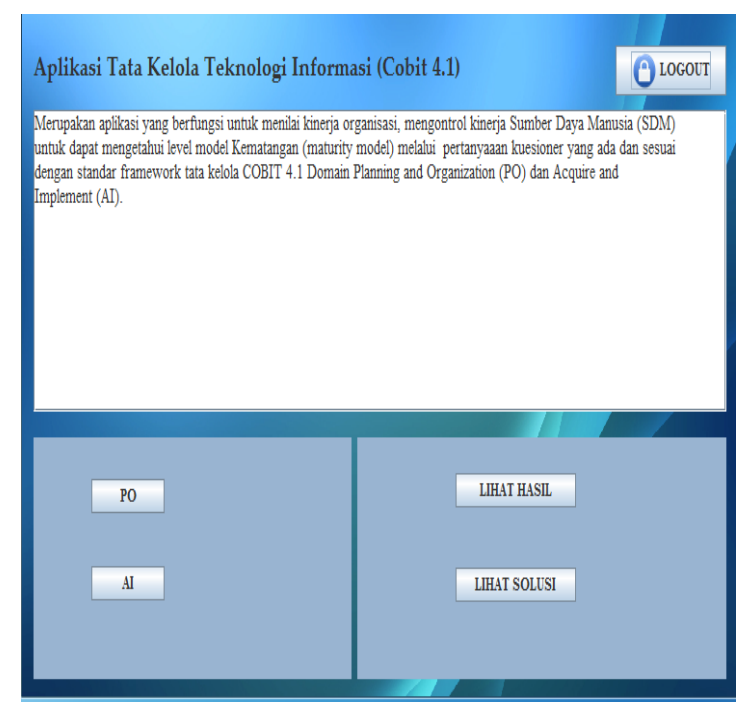

The picture above is the main page screen. On this page, the user can select a questionnaire filling starting from the PO domain and then the AI domain. And also, the user can see the results and solutions of each domain already filled with questionnaires. The logout button is used to return to the login page.

\section{b. Content Page of The Questionnaire}

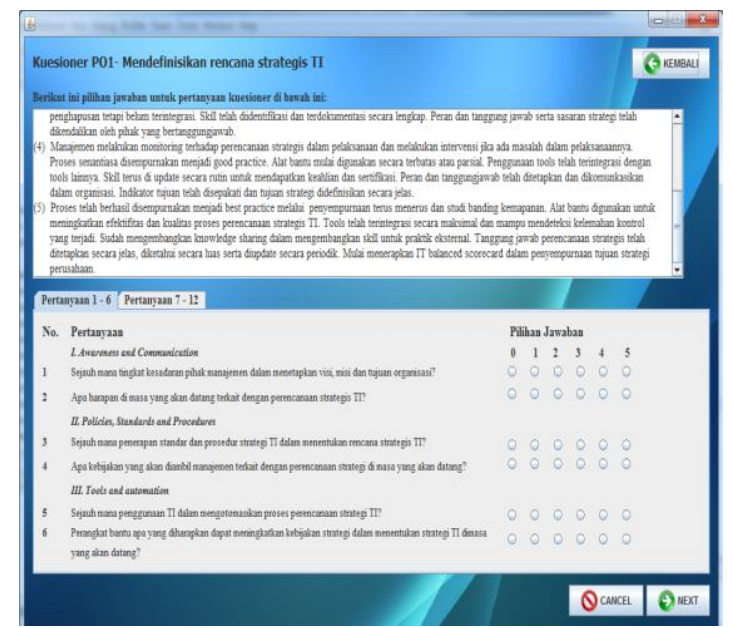

The picture above is the screen of the page filling PO and AI domain questionnaires. Users can fill out a questionnaire by giving a checklist to a selection of answers consisting of a scale of $0-5$, which is the standard level of maturity cobit. 


\section{c. Page View of PO Result}

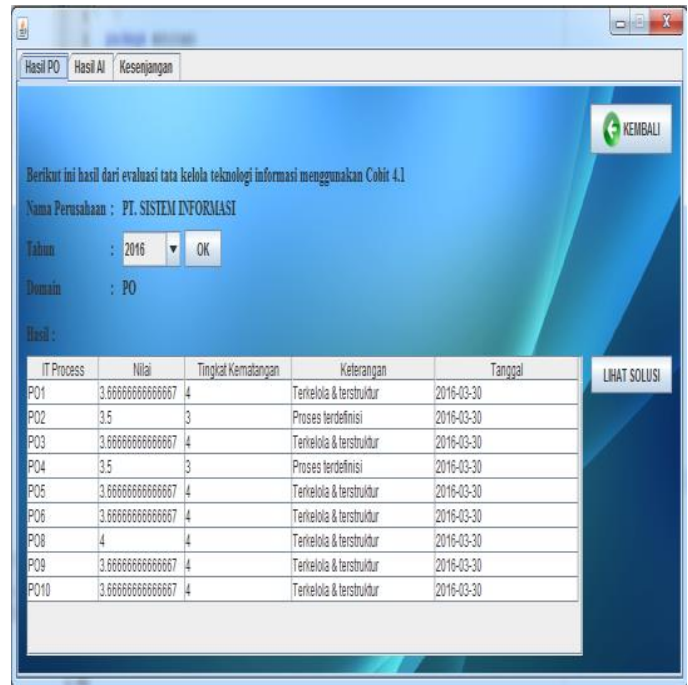

The image above is the result page of the PO in which the result can be calculated from the calculation of PO domain questionnaire. The see solution button is used to see the solution of each domain level achieved. The back button is used to return to the main page.

\section{d. Page View of AI Result}

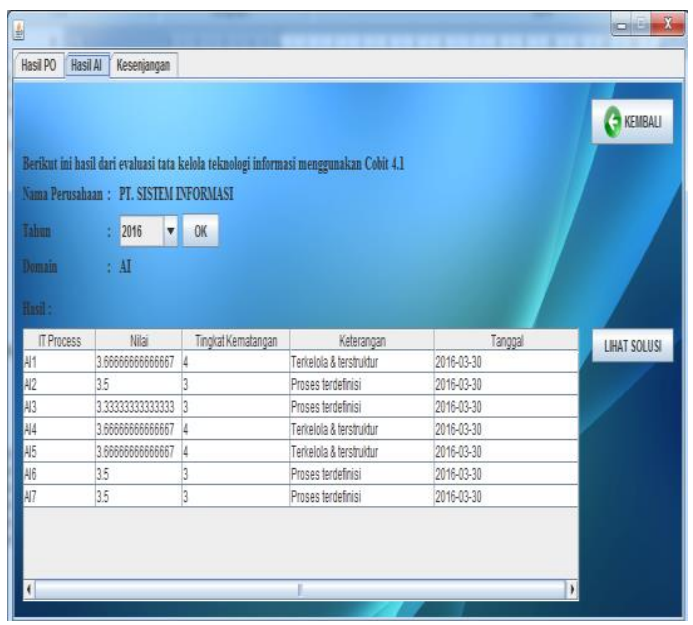

The image above is the AI Result page screen in which result can be calculated from the calculation of AI domain questionnaire. The see solution button is used to see the solution of each domain level achieved. The back button is used to return to the main page. 


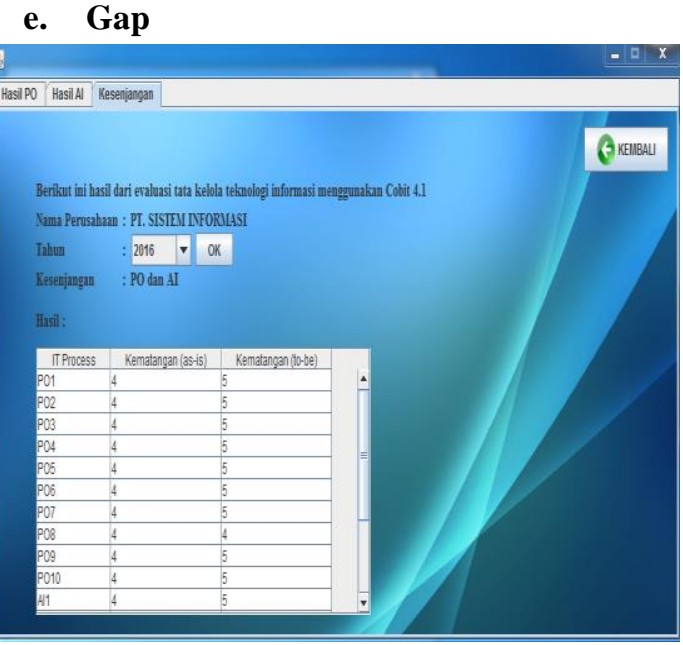

a. View Page of PO Solutions

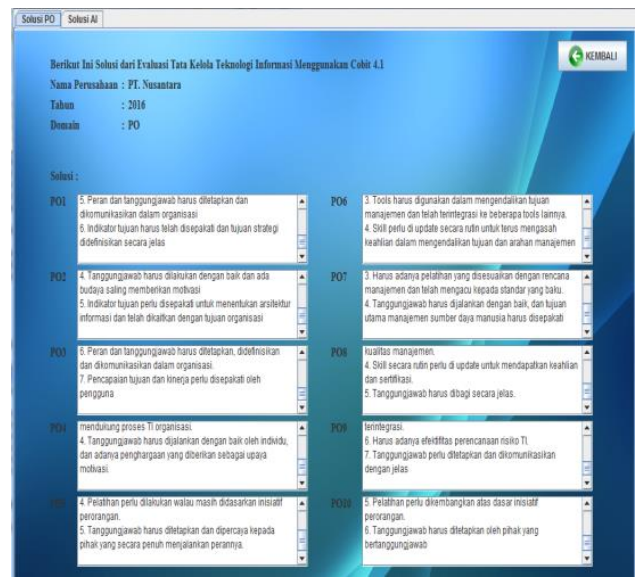

The image above is a view page to the PO domain solution, which is the result of the result page which is then given a solution from each PO domain level so it can rise to a better maturity level.

\section{b. View Page of AI Solutions}

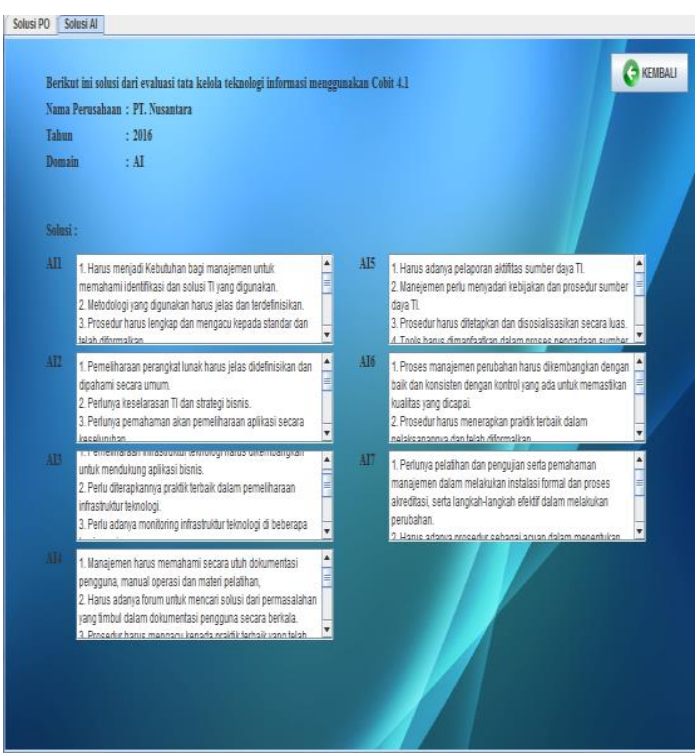


The image above is a view page of the AI domain solution, which is the result of the results page which is then given a solution from each AI domain level so it can move up to a better maturity level.

\section{Conclusion and Recommendation}

\section{A. Conclusions}

After the authors make the implementation of information technology governance application system, it can be concluded that:

1. The Cobit Framework 4.1 is a set of best practices documentation for IT governance that is outlined in the domains, control objectives and existing IT framework processes.

2. Application of information technology governance is needed in SOE companies so they can align corporate business strategy with information technology and achieve target level maturity level (maturity level) TI for SOE at least in maturity level 3 in accordance with Regulation of Minister of SOE No. PER-02 / MBU / 2013.

3. It is expected that this information technology governance application can assist management in decision making and control the performance of human resources (HR) and information technology so that the target of information technology become more effective and efficient, and can support the needs and business goals of the organization.

4. The organization can know the level of achievement level maturity level of the organization based on value rating scale framework Cobit 4.1 .

5. Each maturity level which has been achieved can be improved with a solution that complies with the detail control objectives (DCO) of the Cobit 4.1 framework.

6. The information technology management standards consistent with the Cobit 4.1 framework: business focus, process-oriented, control-based, controlled by measurement, based on maturity models for organizational evaluation, and performance measurement.

\section{B. Recommendations}

As for further refinement, the author intends to convey some suggestions that are as follows:

1. It is hoped that subsequent research can use Cobit's new / new version of information technology governance, and find comparisons with the methods currently used by the authors in this study.

2. It is expected that in the next research can also use Cobit framework combined with other methods to be more detailed in the discussion.

3. The author does not use the object of research in this study, where the next researcher is expected to use the object of research to get more accurate and targeted research results.

\section{Reference}

Association, I. S. (2015). ISACA.

Weber, Ron (1999), Information Systems Control and Audit, The University of Queensland, Prentice Hall. 